\title{
Helicobacter pylori Eradication in Adult Patients with Acute Idiopathic Thrombocytopenic Purpura (ITP)
}

\author{
Minoosh Moghimi 1(D), Yousef Mortazavi 2,3*(D) Saeed Razavi-Dizaji 1D, Shahrbanoo Keyhanian4 (D),

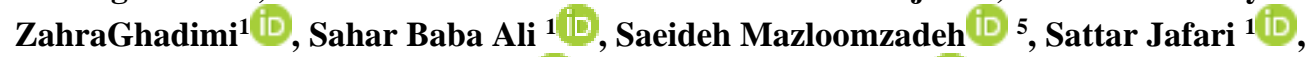 \\ Reza Mansouri iD 1 , Masoud Asadi-Khiavi iD 6, 7
}

1. Dept. of Internal Medicine, Vali-e-Asr Hospital, Faculty of Medicine, Zanjan University of Medical Sciences, Zanjan, Iran

2. Zanjan Metabolic Diseases Research Center, Zanjan University of Medical Sciences, Zanjan, Iran

3. Cancer Gene Therapy Research Center, Zanjan University of Medical Sciences, Zanjan, Iran

4. Dept. of Internal Medicine, Faculty of Medicine, Azad University of Tonekabon, Tonekabon, Iran

5. Social Determinants of Health Research Center, Zanjan University of Medical Sciences, Zanjan, Iran

6. Zanjan Applied Pharmacology Research Center, Zanjan University of Medical Sciences, Zanjan, Iran

7. Dept. of Pharmacotherapy, Faculty of Pharmacy, Zanjan University of Medical Sciences, Zanjan, Iran

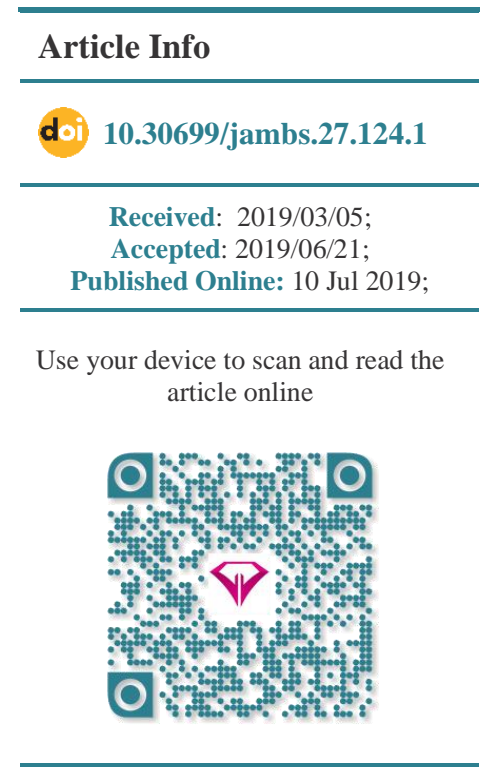

Corresponding Information: Dr Yousef Mortazavi, Cancer Gene Therapy Research Center, Zanjan University of Medical Sciences, Zanjan, Iran, E-Mail: youmort@yahoo.com

\begin{abstract}
Background \& Objective: Different studies have investigated the link between helicobacter pylori (H. pylori) and extra digestive diseases such as idiopathic thrombocytopenic purpura (ITP). However, the relationship between ITP and $H$. pylori is less clear. Most of the studies in ITP have focused on $H$. pylori eradication in chronic ITP, therefore, in this study we e focused on the effect of H. pylori eradication on chronicity of ITP in the adult patients with acute ITP.

Materials \& Methods: Eighty five patients with acute ITP whose platelet counts were less than $30 \times 10^{9} / \mathrm{L}$ entered into the study. Urea breath test (UBT) was carried out for all the patients and based on the results they were divided into 3 groups: Group I: $H$. pylori-positive patients who underwent standard triple therapy. Evaluation of $H$. pylori eradication for this group was carried out in one and six months after the treatment. Group II: ITP patients negative for $H$. pylori and Group III: ITP patients positive for $H$. pylori but without eradication therapy.
\end{abstract}

Results: $52(61.2 \%)$ patients were female and 33 (38.8\%) were male with the mean age of $34.8 \pm 12.2$ years old. There were no significant differences between either the mean age and gender or the mean platelet count at the baseline among the groups, but there was a statistical significant difference in the mean platelet between the groups at the end of the first month. However, significant difference was not seen in the mean platelet count in months 2 to 6 . The chronicity in group I was significantly less than group III. Also, the chronicity rate in non-infected ITP patients was lower than the $H$. pylori-positive patients $(P=0.03)$. Likewise, the chronicity rate was lower in the intervention group than in the control group $(P=0.035)$.

Conclusion: Our results showed that eradication of $H$. pylori can reduce the chronicity rate in adult patients with ITP. Further studies on larger number of patients with longer follow-up are recommended.

Keywords: Chronicity, Helicobacter pylori, Idiopathic Thrombocytopenic Purpura, Platelet, Urea breath test

\section{Introduction}

The term idiopathic thrombocytopenic purpura (ITP) indicates thrombocytopenia without any external etiologic factors, ruling out other diseases associated with secondary thrombocytopenia. ITP is divided into two types; acute and chronic (1). Thrombocytopenia for less than 6 months is indicated as acute ITP. Acute ITP is rare in adults, but over $90 \%$ is converted into chronic form which requires prolonged treatment $(2,3)$.

Helicobacter pylori (H. pylori) is a spiral gramnegative bacteria that colonizes in the mucosal layer of the stomach. It is usually associated with a variety of gastrointestinal disorders including gastric mucosal atrophy, chronic gastritis, peptic ulcer and gastric adenocarcinoma (4-6). 
The exact mechanism of $H$. pylori-associated ITP is still uncertain, but some studies have suggested that cytotoxin-associated gene A (Cag A) stimulates the development of anti-CagA antibodies (Abs). These antibodies may cross-react with the platelet surface antigens resulting in ITP (7).

Helicobacter pylori prevalence in patients with ITP is the same as in other people. Its prevalence is approximately $30 \%$ in the developed countries and more than $80 \%$ in developing countries in adult population. Several studies have shown the relationship between $H$. pylori and gastric diseases, including autoimmune diseases $(\mathbf{8 , 9})$, but this type of relationship is not clear about ITP. For example, elimination of $H$. pylori in the patients with ITP in Japan led to the improvement in disease, but this finding was not confirmed in America. Thus, it is not reasonable to stick to routine testing of $H$. pylori in the patients with ITP. However, some references recommend $H$. pylori testing in adults but it is not applicable in the children with ITP (2). The acute type of ITP in $28 \%$ of children is converted to chronic types which need treatment (1). Acute ITP is rare in adults, but over $90 \%$ is converted into chronic form and require lengthy treatments $(2,3)$. In new references, chronic ITP is the condition with platelet counts lower than $50 \times 10^{9} / \mathrm{L}$ for 3 months and longer as well as lack of response to splenectomy (2). Despite various therapies, ITP in adults is a serious disease compared to children and has a mortality rate of $5 \%$ (mostly due to an intracranial hemorrhage).

Several studies have investigated on $H$. pylori eradication in ITP and reported that $H$. pylori eradication can lead to an increase in platelet counts $(10,11)$. However, other studies were unable to confirm the beneficial effect of bacterial eradication in ITP $(12,13)$.

In a systematic review by Arnold et al., eleven studies were reviewed. It was concluded that $H$. pylori treatment for ITP patients without $H$. pylori infection is of little benefit in comparison with $H$. pyloripositive ITP patients. These data showed that there may be a causal link between $H$. pylori infection and ITP in some patients (14).

In another study, it was concluded that treatment of H. pylori in ITP patients is indicated only in the patients with $H$. pyloripositive test (15). Shaikh et al., in their study showed an association between $H$. pylori and chronic ITP and recommended the eradication of infection in positive cases at diagnosis (16).

In a systematic review conducted by Stasi et al., twenty surveys were appraised and it was revealed that response rates in countries with a higher prevalence of $H$. pylori infection in the patients with milder degrees of thrombocytopenia were higher. As a result, screening for $H$. pylori in Japan and countries with a high prevalence is valuable but for countries like America where the prevalence of $H$. pylori infection and the response rate is low, the cost-benefit ratio should be assessed (17). Semple et al., demonstrated that in the presence of antibodies against platelets, gram-negative bacteria lipopolysaccharide can markedly affect Fc-mediated platelet phagocytosis (18).

Therefore, due to controversial outcome of $H$. Pylori eradication in ITP, the present study was designed to elucidate the role of $H$. pylori eradication as a preventing factor of ITP chronicity.

\section{Materials and Methods}

This investigation was designed as a quasiexperimental study. The cases were collected among all admitted patients with acute ITP and platelet counts less than $30 \times 10^{9} / \mathrm{L}$ during the sampling period in some general Hospitals in Iran. The following variables were considered: age, gender, $H$. Pylori treatment, platelet count and chronic ITP. Criteria for the diagnosis of acute ITP included: 1) Having platelet count less than $30 \times 10^{9} / \mathrm{L}$ with normal WBC, $\mathrm{Hb}$ and ESR, 2) Age of eighteen years and older of both sexes, 3) Having bone marrow aspiration/biopsy (BMA/B) compatible with ITP (if it was required), 4) Ruling out pseudothrombocytopenia, hereditary thrombocytopenia as well as secondary ITP due to human immunodeficiency virus (HIV) infection, autoimmune disorders and drug-induced thrombocytopenia, 5) No history of previous ITP, 6) No history of splenectomy.

From eighty seven cases of acute ITP who entered in this study, two patients were excluded due to the diagnosis of HIV and myelodysplastic syndrome (MDS) and eighty five patients with acute ITP and platelet counts below $30 \times 10^{9} / \mathrm{L}$ were finally enrolled. Because of the low incidence of acute ITP in adults the number of patients was less than anticipated. After identifying patients with acute ITP eligible to participate in the study and also after disease stability regardless of response to treatment, the cases were underwent UBT if they had no history of drug taking to interact with the mentioned test according to their medical histories. In the case of recent drug consumption, UBT was performed after one month of drug discontinuation. Patients were divided into 3 groups based on the UBT results: Group I) eradication of $H$. pylori in infected ITP cases using standard triple therapy by Amoxicillin $1000 \mathrm{mg}$ twice daily, and Clarithromycin $500 \mathrm{mg}$ twice daily and Pantoprazole $40 \mathrm{mg}$ twice daily for 7 days, Group II) H. pylori uninfected cases with standard treatment of ITP) and Group III) patients infected with $H$. pylori which did not receive eradication therapy. All patients received standard therapy included corticosteroid with or without intravenous immunoglobulin (IVIG). UBT was carried out at the first and the six ${ }^{\text {th }}$ month after the onset of therapy. 
Table 1. Comparisons of mean platelet counts in 3 groups during the study (mean \pm SD)

\begin{tabular}{|c|c|c|c|c|}
\hline $\begin{array}{l}\text { Time of platelet } \\
\text { counting }\end{array}$ & $\begin{array}{l}\text { Group I } \\
\text { PIt no/uL }\end{array}$ & $\begin{array}{l}\text { Group II } \\
\text { PIt no /uL }\end{array}$ & $\begin{array}{l}\text { Group III } \\
\text { Plt no/uL }\end{array}$ & $\begin{array}{c}P \text { - } \\
\text { value }\end{array}$ \\
\hline $\begin{array}{l}\text { At the beginning of } \\
\text { study }\end{array}$ & $7161 \pm 5222$ & $9000 \pm 5649$ & $8866 \pm 7233$ & 0.34 \\
\hline $\begin{array}{l}\text { At the end of the } 1^{\text {st }} \\
\text { month }\end{array}$ & $59258 \pm 43570$ & $107958 \pm 88983$ & $50233 \pm 34708$ & 0.001 \\
\hline $\begin{array}{l}\text { At the end of the } \\
2^{\text {nd }} \text { month }\end{array}$ & $96903 \pm 46286$ & $112916 \pm 77229$ & $100933 \pm 67747$ & 0.64 \\
\hline $\begin{array}{l}\text { At the end of the } \\
3^{\text {rd }} \text { month }\end{array}$ & $128580 \pm 54800$ & $139958 \pm 64889$ & $121933 \pm 62709$ & 0.55 \\
\hline $\begin{array}{l}\text { At the end of the } 4^{\text {th }} \\
\text { month }\end{array}$ & $151645 \pm 65400$ & $148666 \pm 69850$ & $138226 \pm 70035$ & 0.73 \\
\hline $\begin{array}{l}\text { At the end of the } 5^{\text {th }} \\
\text { month }\end{array}$ & $157225 \pm 61809$ & $153875 \pm 77440$ & $147733 \pm 69209$ & 0.86 \\
\hline $\begin{array}{l}\text { At the end of the } 6^{\text {th }} \\
\text { month }\end{array}$ & $170741 \pm 55390$ & $162916 \pm 71482$ & $157400 \pm 79446$ & 0.75 \\
\hline
\end{tabular}

In the first group, the patients whose $H$. pylori infection were not eradicated (UBT was positive in the first month) or the patients who had recurrent infection (UBT was positive at the end of the six $^{\text {th }}$ month) were transferred from group I to group III and data analysis was done with and without them. These groups received standard treatment for ITP. The platelet count was measured every month up to six months after the start of the treatment. All data required for this study included age, sex, time of entry into the study, tests requested, and date of treatment which were entered into the questionnaires.

Inclusion criteria were as follows: 1) Patients over eighteen years of age, 2) Patients who have not been elapsed from disease onset more than six months (acute ITP), 3) Other causes of thrombocytopenia were excluded. Exclusion criteria for the study were as follows: 1) A serious illness such as heart, liver and kidney diseases, and neoplastic disorders, 2) History of previous treatment for $H$. pylori, 3) Allergic reaction to therapies used for $H$. pylori, 4) Distinct gastrointestinal signs and symptoms for the pharmacologic intervention as well as treatment for $H$. pylori, 5) Secondary causes of ITP.

Chi-square (for qualitative variables), independent t-test (in the case of normally distributed quantitative variables) and Mann-Whitney $U$ test (in the case of non-normal distribution of quantitative variables) were used for the statistical analysis.

In view of medical ethics, there was no compulsion to participate in the study. All patients were initially explained that the information was completely confidential and used solely for the scientific goals. Also, unknown effect of $H$. pylori treatment on patients with ITP was explained to the patients and a written informed consent was obtained from all the participants.
Ethically, there was no need to treat all patients with positive UBT, because all the patients with $H$. pylori did not have indications for treatment. Additionally, cases with indication for $H$. pylori treatment (like peptic ulcer histories) were excluded.

\section{Results}

UBT was positive in sixty one patients $(71.8 \%)$. Thirty seven of them $(60.6 \%)$ were female and twenty four $(39.4 \%)$ were male. UBT in twenty four patients (28.2\%) was negative; among them fifteen $(62.5 \%)$ were female and nine $(37.5 \%)$ were male.

Thirty six patients (UBT positive group I cases) underwent eradication of infection. Twenty four patients in the second group (UBT negative cases) and twenty five patients in group III (UBT positive cases without eradication of infection) were enrolled. Three cases of group I and two cases of group II were excluded due to lack of $H$. Pylori eradication and infection recurrence at the end of the $6^{\text {th }}$ month, respectively. These cases were placed in group III and analysis was carried out with and without them. No significant difference was observed between gender and age of the patients in 3 groups.

The mean platelet count in different groups was not statistically significant at the beginning of the study $(P=0.34$, Table 1). At the end of the first month, mean differences of platelet counts between 3 groups of patients was statistically significant $(P=0.001$, Table 1). There was a significant difference between platelet mean in groups I and II $(P=0.01)$ as well as groups II and III $(P=0.002)$ at the end of the first month, but there was no significant difference between groups I and III $(P=0.83)$. There were no significant statistical differences between mean platelet count in 3 groups after the end of the second month to six months 
$(P=0.64,0.55,0.73,0.86$ and 0.75 , respectively). It is noteworthy that the mean platelet count difference between the groups excluding 5 transmitted patients from group I to group III, showed no statistically significant difference during the second to six $^{\text {th }}$ months either.

Platelet count higher than $100 \times 10^{9} / \mathrm{L}$ was considered as a cutoff point for the assessment of chronicity at the end of the six ${ }^{\text {th }}$ month. There was no significant difference between groups I and II in terms of chronicity $(P=0.22)$. However, chronicity of the disease in group I was statistically significant and much lower than group III $(P=0.018)$. The disease chronicity in group I without excluded 5 transferred cases ( 3 refractory patients and 2 patients with relapsed $H$. pylori infection) was significantly lower than group III $(P=0.016)$ at the end of the six ${ }^{\text {th }}$ month. The chronicity rate in the patients without $H$. pylori infection (Total Groups I and II) was significantly lower than in the patients with $H$. pylori infection (group III), $(P=0.03)$. The mean platelet count elevation in groups I, II and III between the baseline and the end of the six ${ }^{\text {th }}$ month showed no significant difference $(P=0.64)$. No significant difference was also observed between treatment groups at the end of the $\operatorname{six}^{\text {th }}$ month $(P=0.67$, Table 2).

As it is shown in Table 3, the likelihood of having platelet count higher than $100 \times 10^{9} / \mathrm{L}$ was 0.14 in group III compared to group I $(P=0.02)$ which showed significant effect of $H$. Pylori eradication on ITP chronicity despite age, gender, splenectomy and baseline platelet count.

Table 2. Comparison of different treatment procedures performed during the study

\begin{tabular}{ccccc} 
Procedure & Group I & Group II & Group III & Total \\
Corticosteroid therapy & $25(80.6 \%)$ & $20(83.3 \%)$ & $21(70 \%)$ & $66(77.6 \%)$ \\
Splenectomy & $4(12.9 \%)$ & $2(8.3 \%)$ & $4(13.3 \%)$ & $10(11.8 \%)$ \\
\hline Others* & $2(6.5 \%)$ & $2(8.3 \%)$ & $5(16.7 \%)$ & $9(10.6 \%)$ \\
Total & $31(100 \%)$ & $24(100 \%)$ & $30(100 \%)$ & $85(100 \%)$ \\
\hline
\end{tabular}

$P=0.67$

*Others: Rituximab, Cellcept, Cyclophosphamide, Cyclosporine, Azathioprine

Table 3. The logistic regression model results of $\mathrm{H}$. Pylori eradication on ITP chronicity in association with and without age, gender, splenectomy and baseline platelet count

\begin{tabular}{|c|c|c|c|c|}
\hline & ariable & Odds ratio & $(95 \%) \mathrm{CI}$ & P-value \\
\hline \multirow{2}{*}{$\begin{array}{l}\text { H. Pylori } \\
\text { eradication }\end{array}$} & $\begin{array}{c}\text { Group I (with } H . \text { Pylori } \\
\text { eradication) }\end{array}$ & 1.00 & ------ & ------ \\
\hline & $\begin{array}{c}\text { Group III (without } H \text {. Pylori } \\
\text { eradication) }\end{array}$ & 0.14 & $0.03-0.75$ & 0.02 \\
\hline Age & \multicolumn{2}{|l|}{1.003} & $0.942-1.068$ & 0.922 \\
\hline \multirow{2}{*}{ Gender } & Female & 1.00 & ------ & ------ \\
\hline & Male & 0.95 & $0.22-4.04$ & 0.94 \\
\hline $\begin{array}{c}\text { Baseline platelet } \\
\text { count }\end{array}$ & \multicolumn{2}{|l|}{1.00} & 1.00 & 0.22 \\
\hline \multirow{2}{*}{ Splenectomy } & No & 1.00 & ------ & ------ \\
\hline & Yes & 1.99 & $0.2-19.8$ & 0.55 \\
\hline
\end{tabular}

\section{Discussion}

A link between ITP and $H$. pylori infection was proposed by Gasbarrini et al., who showed a significant increase in platelet count after $H$. pylori eradication in ITP patients infected with these bacteria (19).
Eradication of $H$. pylori infection has been variably associated with a platelet response in the patients with ITP. The response occurs in some ITP patients infected with this bacterium but not in all patients. Eradication 
therapy seems to be more effective in the patients with less severe ITP (platelet count $>30 \times 10^{9} / \mathrm{L}$ ) and a shorter duration of disease. Most of the studies regarding $H$. pylori infection and ITP have been carried out on the patients with chronic ITP, but patients with chronic ITP have already experienced various treatments that have affected their platelet count. Therefore, the present survey on acute ITP in adults is one of the few existing studies. According to our results, no significant difference was observed for ITP chronicity at the end of the six ${ }^{\text {th }}$ month between the groups with and without $H$. pylori infection. The first report about ITP patients whom $H$. pylori infection were eradicated was provided by Gasbarrini et al., (19) and some studies were conducted by other investigators (20-23). Gan et al., found that the overall platelet response rate was $30 \%$ which was similar to those reported in America but was lower compared to the studies done in Japan and Europe. They also showed that there was no platelet recovery in the patients who demonstrated initial response (24). Baseline platelet count over $30 \times 10^{9} / \mathrm{L}$ and previous treatments for ITP, such as prednisone, are factors that affect the response to eradication of $H$. pylori infection. In our study, the patients had no history of treatment with corticosteroids. However, our study differs from other studies due to the inclusion of patients with a platelet count less than $30 \times 10^{9} / \mathrm{L}$. Veneri et al., showed that there was no significant benefit of $H$. pylori infection eradication in the patients with marked thrombocytopenia, however, they showed that early eradication therapy was more effective in their patients as the thrombocytopenia was moderate (25). Our study suggests that $H$. pylori infection may be a cause of ITP chronicity which is hoped to be controlled by eradicating infection. The mechanism by which $H$. pylori may cause ITP has not been established, but a chronic immunological stimulation or immunological mimicry between $H$. pylori antigens and platelet has been proposed as a cause of ITP (16). The protein CagA (cytotoxin associate gene-A) is one of the molecules which has molecular cross-reaction with platelets. This protein is more prevalent in Asian countries (such as Iran, Korea and Japan) than in Western countries (18). As a result of $H$. pylori eradication, Cag-A antibody is disappeared and the platelet count is increased in ITP patients. Difference in $H$. pylori antigen genotype (prevalence of $H$. pylori with positive Cag-A) may be increased in the patients with ITP and platelet which influence the treatment outcome. Although, we have not tested for the presence or absence of this protein in our patients, the significant differences seen in ITP chronicity in our groups may be due to the differences in H. pylori Cag-A protein. In most studies, cases with a slight decrease in platelet count have shown a better response to treatment (4). Suzuki et al., found that the eradication of $H$. pylori infection in the patients with ITP was associated with a platelet response of $46.2 \%$ in the eradication group and $0 \%$ in non-eradication group. They also showed that the platelet response was significantly more common in the patients with infection sustained by CagA-positive strains of $H$. pylori (22).

Prevalence of ITP at older age in $H$. pylori-positive patients compared to $H$. pylori-negative patients may be related to the long-term underlying susceptibility to H. pylori infection $(3,22)$. However, in our study there was no significant difference between the groups in terms of age. The results of our study indicated that eradication of $H$. pylori infection in the patients with acute ITP will prevent the chronicity of the disease because the platelet count higher than $30 \times 10^{9} / \mathrm{L}$ in groups I and II (which were negative for $H$. pylori infection at the end of the six ${ }^{\text {th }}$ month) was more common than in group III (H. pylori infection at the end of the $\operatorname{six}^{\text {th }}$ month). These results showed an association between $H$. pylori infection and ITP, thus, eradication of $H$. pylori can diminish the chronicity of ITP. At least in part, these findings suggest that screening of the patients with acute ITP in order to eradicate $H$. pylori infection can prevent ITP chronicity in a number of patients with $H$. pylori infection. Finally, we should mention that the results of the present study cannot be compared with the studies that have been conducted on the patients with chronic ITP infected with $H$. pylori, because the patients with chronic ITP have already a milder or moderate thrombocytopenia due to use of corticosteroids. Rather, patients with acute ITP and severe thrombocytopenia were entered in our study and received corticosteroids afterwards.

\section{Conclusion}

Our study confirm some of the previous results and suggest that $H$. pylori infection may be a cause of ITP. Therefore, eradication of $H$. pylori infection in patients with acute ITP may prevent the chronicity of ITP. However, further studies on larger number of infected and non-infected patients with acute ITP are recommended to confirm these results.

\section{Acknowledgments}

We are grateful to all patients who participated in this study. Dr Moghimi designed the project and contributed to the drafting. Dr Mortazavi, Dr Keyhanian, Dr Mansouri and Dr Asadi-Khiavi 
contributed to the design of research study and also drafting the manuscript. Dr Mazloomzadeh analyzed the data and Dr Razavi-Dizaji, Miss Ghadimi and Miss Baba Ali contributed to the reagents, Lab works and experiments. This work was fully supported by the grant from Zanjan University of Medical Sciences, Zanjan, Iran.

\section{Conflict of Interest}

Authors declared no conflict of interest.

\section{References}

1. Neunert CE. Current management of immune thrombocytopenia. Hematology Am Soc Hematol Educ Program. 2013; 2013: 276-82. [DOI:10.1182/asheducation-2013.1.276]

2. Provan D, Stasi R, Newland AC, et al. International consensus report on the investigation and management of primary immune thrombocytopenia. Blood. 2010; 115(2):168-86. [DOI:10.1182/blood2009-06-225565]

3. Longo D , Fauci A, Kasper D , et al . Harrison's Principle of Internal Medicine. 18thed. Vol 1\&2, McGraw-Hill, NewYork, 2012. 965-69.

4. Hee Sang Tag, Ho Sup Lee, Su-Hyeon Jung, et al. Effects of Helicobacter pylori eradication in patients with immune thrombocytopenic purpura. Korean J Hematol .2010;45(2): [DOI:10.5045/kjh.2010.45.2.127]

5. Suerbaum S, Michetti P. Helicobacter pylori infection. New Eng J Med. 2002, 347(15): 1175-86. [DOI:10.1056/NEJMra020542]

6. Kim YI, Cho SJ, Lee JY, et al. Effect of Helicobacterpylori eradication on long-term survival after distal gastrectomy for gastric cancer. Cancer Res Treat.2016; 48 (3); 1020-29. [DOI:10.4143/crt.2015.264]

7. Vanegas YAM, Vishnu P. Management of Helicobacter pylori in patients with immune thrombocytopenia. Hamostaseologie. 2019; 39(3):279-83 19. doi: 10.1055/s-0039-1683974 [Epub ahead of print]. [DOI:10.1055/s-00391683974]

8. Emilia G, Longo G, Luppi M, et al. Helicobacter pylori eradication can induce platelet recovery in idiopathic thrombocytopenic purpura. Blood. 2001;97:812-814. [DOI:10.1182/blood.V97.3.812]

9. Sato R, Murakami K, Watanabe K, et al. Effect of Helicobacter pylori eradication on platelet recovery in patients with chronic idiopathic thrombocytopenic purpura. Arch Intern Med. 2004;164:1904-7. [DOI:10.1001/archinte.164.17.1904]

10. Stasi R, Rossi Z, Stipa E, Amadori S, Newland A, Provan D. Helicobacter pylori eradication in the management of patients with idiopathic thrombocytopenic purpura. Am J Med. 2005;118 (4): 414-19. [DOI:10.1016/j.amjmed.2004.09.014]

11. InabaT, Mizuno $M$, Take $S$, et al. Eradication of Helicobacter pylori increases platelet count in patients with idiopathic thrombocytopenic purpura in Japan. Eur J Clin Invest. 2005; 35(3): 214-19. [DOI:10.1111/j.1365-2362.2005.01471.x]

12. Treepongkaruna S, Sirachainan N, Kanjanapongkul $\mathrm{S}$, et al. Absence of platelet recovery following Helicobacter pylori eradication in childhood chronic idiopathic thrombocytopenic purpura: a multi-center randomized controlled trial. Pediatric Blood \& Cancer. 2009; 53(1): 72-77. [DOI:10.1002/pbc.21991]

13. Tang $\mathrm{Y}$, Wang SC, Wang $\mathrm{LJ}$ et al. Clinical significance of Helicobacter pylori in children with idiopathic thrombocytopenic purpura. Zhongguo Shi Yan Xue Ye XueZaZhi. 2013; 21(2): 419-21.

14. Arnold DM , Bernotas A, Nazi I, et al. Platelet count $r$ esponse To H. Pylori treatment in patients with immune thrombocytopenic purpura with and without H. Pylori infection: A systematic review. Haematologica. $\quad 2009 ; \quad 94: \quad 850-56$. [DOI:10.3324/haematol.2008.005348]

15. Arnold DM,Stasi R. Does Helicobacter pylori eradication therapy result in a platelet count improvement in adults with immune thrombocytopenic purpura regardless of H.pylori infection? Hematology Am Soc Hematol Educ Program.2008;2008: $31-2$. [DOI:10.1182/asheducation-2008.1.31]

16. ShaikhK H, Ahmed S, Ayyub M, Anwar J. Association of Helicobacter Pylori infection with Idiopathic Thrombocytopenic Purpura. J Pak Med Assoc .2009; 59(10):660-3.

17. Stasi R, Sarpatwari A, Segal JB, et al. Effects of eradication of Helicobacter pylori infection in patients with immune thrombocytopenic purpura: a systematic review. Blood. 2009; 113: 1231-40. [DOI:10.1182/blood-2008-07-167155]

18. Semple JW, Aslam R, Kim M, Speck ER, Freedman J. Platelet-bound lipopolysaccharide enhances $\mathrm{Fc}$ receptor-mediated phagocytosis of IgG-opsonized platelets. Blood. $2007 \quad ; 109(11)$ :4803-5. [DOI:10.1182/blood-2006-12-062695]

19. Gasbarrini A, Franceschi F, Tartaglione R, Landolfi R, PolaP,Gasbarrini G. Regression of autoimmune thrombocytopenia after eradication of Helicobacter pylori. Lancet, $1998, \quad 352(9131)$ : 878. [DOI:10.1016/S0140-6736(05)60004-9]

20. Inaba $\mathrm{T}$, Mizuno $\mathrm{M}$, Take $\mathrm{S}$, et al. Eradication of Helicobacter pyloriincreases platelet count in patients with idiopathic thrombocytopenic purpura in Japan. Eur J Clin Invest, 2005; 35(3):214-9. [DOI:10.1111/j.1365-2362.2005.01471.x]

21. Kohda K, Kuga T, Kogawa K, et al. Effect of Helicobacter pylori eradication on platelet recovery in Japanese patients with chronic idiopathic thrombocytopenic purpura and secondary autoimmune thrombocytopenic purpura. $\mathrm{Br} \quad \mathrm{J}$ 


\begin{abstract}
Haematol. 2002; $\quad$ 118:(2):584-8.
\end{abstract} [DOI:10.1046/j.1365-2141.2002.03612.x]

22. Suzuki T, Matsushima M, Masui A, et al. Effect of Helicobacter pylori eradication in patients with chronic idiopathic thrombocytopenic purpura. A randomized controlled trial. Am J Gastroenterol. 2005; 100 (6):1265-70. [DOI:10.1111/j.15720241.2005.41641.x]

23. Song MK, Chung JS, Shin HJ, Choi YJ, Cho GJ. Outcome of immunosuppressive therapy with Helicobacter pylori eradication therapy in patients with chronic idiopathic thrombocytopenic purpura. J
Korean Med Sci. 2008; 23(3): 445-51. [DOI:10.3346/jkms.2008.23.3.445]

24. Gan GG, Norfaizal AL, Bee PC, Chin EF, Habibah $\mathrm{AH}$, Goh KL. Helicobacter pylori infection in chronic immune thrombocytopenic purpura patients in Malaysia. Med J Malaysia. 2013; 68 (3): 231-3.

25. Veneri D, Bonani A, Franchini M, Fedrizzi A, Pizzolo G. Idiopathic thrombocytopenic and Helicobacter pylori infection: platelet count increase and early eradication therapy. Blood Transfus. 2011; 9(3): 340-2.

\section{How to Cite This Article:}

Moghimi M, Mortazavi Y, Razavi-Dizaji S, Keyhanian S, Ghadimi Z, Baba Ali S, et al. . Helicobacter pylori Eradication in Adult Patients with Acute Idiopathic Thrombocytopenic Purpura (ITP). J Adv Med Biomed Res. 2019; $27(124): 1-7$

\section{Download citation:

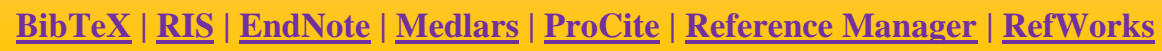

\section{Send citation to:}

Q Mendeley 2 Zotero [i) RefWorks $\underline{\text { RefWorks }}$ 